\title{
Development of Human Milk Fat Analogues: A review on Techniques and Accomplishments
}

\author{
Keshav Rajarshi ${ }^{1 *}$ \\ ${ }^{1}$ School of Community Science and Technology (SOCSAT) Indian Institute of Engineering \\ Scince and Technology (IIEST), Shibpur, Howrah, West Bengal-711103, India \\ Email: keshavrjr@gmail.com \\ *Correspondence should be addressed to this author
}

Keywords: Human Milk Fat, TAG, DHA, Fatty Acids, Nutrients, Food Industry, Structured Lipids, LCPUFA, Interesterification, Acidolysis, PA 


\begin{abstract}
Maternal milk, from well-nourished and healthy mothers, is a source of several bioactive compounds and balanced nutrients required for proper growth and development of the infant. Hence it is regarded as the optimal form of nourishment. Human milk fat from human milk is the most crucial component and is a necessity for the growing infant. However, in certain cases, the breast milk may fulfill the nutritional needs or the breast-feeding of the infant is not feasible; infant formulae are then considered as the best alternative as nutritional support. It becomes essential for the infant formula to behave and provide nutritive support in the same way as human milk. In order to achieve so, the most crucial components of all should also be prepared precisely, i.e., the analogue of human milk fat. This analogue, which mimics the actual human milk fat, can be then used as a prime ingredient while designing the infant formula. Significant research and several advances have been made in preparing the infant formula enriched with adequate fat content, and more studies are still being conducted in order to achieve a more sound product in the most economical and simplest way possible.
\end{abstract}

\title{
1. Introduction
}

\subsection{What is a Human Milk Fat Analogue?}

Human milk is considered as a complete and balanced diet for infants. Breast-feeding is regarded as the most suitable feeding methodology [1]. However, in case of the unavailability of human milk due to any unfortunate reason, infant formulae are considered to be the best alternative for human milk. Besides being rich in energy, fats contain several essential fatty acids, hormones, and several other fat-soluble vitamins that are essentially required for the growth of the infant. Thus, fats are very crucial components of milk. Human milk consists of approximately $3-5 \%$ of fats, but more than $50 \%$ energy requirement for infants is provided by these fats $[2,3]$.

Complex natural lipids are abundantly present in the human milk fat as it accounts for more than 400 triacylglycerols (TAGs) [4] and 200 fatty acids (FAs) [2], thus comprising around $98 \%$ of the human milk [5]. Several other complex lipids are also present in the human milk, including sphingolipids, glycerophospholipids, sterol lipids, all of which are arranged in unique molecular structures and configurations. Being the most variable constituent of the human milk, fat's composition and content are mainly regulated by various factors such as an individual's diet, the period of lactation, and individual differences [2]. When compared to various other naturally occurring lipids, it was found that the human milk fats are significantly 
different. For e.g., the distribution of palmitic acid (PA, 16:0) in human milk's TAGs is different when compared to other mammalian milk fats and vegetable oils. The saturated fatty acids (palmitic acid) are primarily found at the sn-2 position, whereas other unsaturated fatty acids are esterified at $s n-1,3$ position of the glycerol backbone. Regulation of TAG metabolism, including digestion and absorption in infants, is influenced by this special distribution of HMF $[6]$.

In certain foods for medical purposes or infant formulae, Human Milk Fat Analogues/Substitutes (HMFA/S) is used. These HMFAs are, basically, modified lipids obtained from natural fats in order to imitate human milk fat. The past few years witnessed the successful development and commercialization of several HMFAs. These HMFAs emerged as energy supplements, an essential fatty acid source, and nutritional supplements.

HMFAs are designed via the chemical and enzymatic modification of the natural lipids and have successfully piqued the interest of scientists due to their effects on the development and growth of the infants who are dependent on IF and growth supplements.

\section{Design and production of HMFA: A brief history}

The developmental phases of HMFA development and commercialization can be addressed as "waves". Through several waves of innovation and scientific interventions, the application of HMFAs in IF have reached the present level. The first wave of the HMFA dates back to the $19^{\text {th }}$ century. In the year 1867 , a German chemist Justus von Liebig invented the first commercial infant formula known as "soup for babies". It contained a mixture of cow's milk, potassium bicarbonate, wheat, and malt flour. Initially, the formula was produced in liquid form, but later, a powdered version with decreased fat content (skimmed cow's milk) was also introduced [7].

As a result of scientific innovations and studies during the $20^{\text {th }}$ century, researchers then had an enhanced understanding of the composition of milk, and differences between human and cow milk. Thus, during the second wave of HMFAs, they tried to develop a human milk formula which had a somewhat similar composition to that of the human milk. This formula had augmented digestive capabilities for infants [8, 9]. An American paediatrician, Henry John Gerstenberger developed a product in 1915, which he called 'humanised product'. This 'humanised product was synthetic milk adapted (SMA), [10], which was comprised of several vegetable oils. The ratio of macronutrients including fats, proteins and carbohydrates were all 
similar to that of the human milk. It also matched human milk's fatty acid composition. The addition of cod liver oil was introduced in the 1920s in order to provide a source for vitamin D in the infant formulae [10]. During the 1920s, the primary composition of these infant formulae was the combination of vegetable oils and butterfat (top layer obtained after centrifugation).

The third wave of HMFAs started in the late 1990s, and we are living in the third wave. The composition of human milk fat has been extensively investigated because of the development of lipidomic analysis and revolutions in the field of mass spectrometry (MS). Researchers are continuously trying to produce infant formulae that reliably mimic human milk fat. The development of long-chain polyunsaturated fatty acids (LCPUFAs) was one of the biggest breakthroughs in the HMFA development. These LCPUFAs are composed of AA (arachidonic acid), EPA (eicosapentanoic acid), and DHA (docosahexanoic acid). These fatty acids are crucial for cognitive and visual development in infants. LCPUFAs became a mandatory constituent of the infant formulae, as suggested by different legislations in the early 2000s. [7]

The development of $s n$-2 palmitates, primarily 1,3-dioleoyl-2-palmitoyl-glycerol (OPO), was another breakthrough. The scientists realized the fact in the 1990s that the structure of TAG, i.e., the fatty acid distribution on the glycerol backbone, could affect the metabolism and absorption of fat $[6,11]$. Palmitic acid is mainly found to be attached to the $s n-1,3$ positions of the glycerol backbone in the case of the vegetable oil, whereas in human milk fat, PA is abundantly (>70\%) found at the $s n-2$ position. Fatty acid distribution modification on the TAGs was made possible by specialized enzymes and their usage at the industrial scale [12] [13, 14] [15].

The specifically structured triacylglycerols (SSTs) were produced by the $s n-1,3$ lipasecatalyzed regiospecific interesterification reaction [15] [13]. The vegetable oil derived SSTs are $s n-2$ palmitates that have a similar positional distribution and composition as the human milk fat. The first $s n-2$ palmitate was introduced in the market as Betapol $₫$ and was developed by IOI Loders Croklaan. Its first usage in infant formulae dates back to 1995 [7]. China, in 2008 , declared the application of $s n-2$ palmitate products legal in IF as nutritional supplements.

The IF that is found today is a complex mixture of more than 100 components. Fats present in the IF are too complex mixtures comprised of oils and fats derived from various sources like vegetables, cow' s/goat's milk, and microbial sources. Different brands in different countries use varying fat composition in their IF. For e.g., lard, being one of the few natural fat sources 
containing abundant TAGs with PA at $s n-2$ position, is being used in IF in Japan. However, due to labelling issues and safety, lard is banned from being used in IF in most of countries.

\section{Human Milk and HMF: What do we know so far?}

\subsection{Human Milk and its nutritional composition}

Human milk constitutes hundreds to thousands of distinct biologically active molecules that prevent inflammation and infection and contribute towards organ development, immune maturation/regulation, and colonization of healthy microbes. Molecules like lactoferrin are considered as novel therapeutic agents and are under investigation. Human milk is a bioactive, dynamic fluid that undergoes changes in its composition from colostrum to late lactation. It varies with diurnally, feeds, and among mothers. Nowadays, the usage of expressed milk for feeding infants is increasing. In the United States, most mothers express and freeze their milk at a particular point during lactation for feeding the infants in the future. In the case of highrisk infants, pasteurized donor milk is administered now commonly.

The nutritional constituents of the milk are derived from three main sources: some milk nutrients are dietary in origin, some originate from maternal stores, and some are synthesized in the lactocyte.

\subsection{Macro and micronutrients}

Across lactation and among mothers, the composition of macronutrients varies but is significantly conserved across the populations, although there may be variations in the nutritional status of the mother [16]. A mature, term milk consists of approximately 3.2 to 3.6 $\mathrm{g} / \mathrm{dL}$ fat, 0.9 to $1.2 \mathrm{~g} / \mathrm{dL}$ protein and 6.7 to $7.8 \mathrm{~g} / \mathrm{dL}$ lactose. The range of energy estimates are from 65 to $70 \mathrm{kcal} / \mathrm{dL}$ and are proportional to the fat content of human milk. A study conducted in Davis, California, investigated the relationship between macronutrient composition of human milk and maternal characteristics and revealed that after four months following the childbirth, the concentration of macronutrients associated with human milk is influenced by factors including maternal protein intake, menstruation return, maternal body weight with respect to height and nursing frequency. It was also found in this study that mothers producing milk in high quantities have low fat and protein concentrations in the milk while having a higher concentration of lactose [17]. The contribution of the prime macronutrients has been illustrated in Figure 1 [18]. 
Similar to the macronutrients, the concentration of micronutrients in human milk is also influenced by diet intake by the mother and amount of vitamins and minerals present in the maternal body, including vitamins A, B1, B2, B6, B12, D, and iodine. Consumption of multivitamins is recommended during lactation as maternal diet is not always optimal $[19,20]$.

\subsection{Milk fats and lipids}

Milk is identified as an emulsion of globules of fats in an aqueous liquid. These distinct milk fat globules are synthesized in the mammary alveolar cells and contain a core of non-polar lipids mainly made up of TAGs, with small amounts of diglycerides, monoglycerides as well as non-esterified fatty acids. The formation of these non-polar lipids takes place in the ER (endoplasmic reticulum). In the ER they are synthesized from the fatty acids obtained from primarily intermediate chain fatty acids with 12 or $14 \mathrm{C}$-atoms synthesized from acetyl-CoA as well as the maternal circulation. Phospholipids, sphingolipids, and plasmalogens constitute about $0.2-1 \%$ of the total milk lipid or $100-400 \mathrm{mg} / \mathrm{L}$ [21].

Human milk fats contain some LCPUFA (long-chain polyunsaturated fatty acids) such as arachidonic acid (AA, n-6), docosahexanoic acid (DHA, n-3), eicosapentanoic acid (EPA, n3), and docosapentanoic acid (DPA, n-3). A very small portion of HMF is accounted for by LCPUFA, less than $1 \%$ to be precise, individually. Despite this, they are of far greater importance for the development of infants, especially DHA $(0.32 \pm 0.22 \%)$ and AA $(0.47 \pm$ $0.3 \%$ ) [22]. AA and DHA are essential in neuronal function and phototransduction. These are highly concentrated in the phospholipid bilayer of the biologically active retinal neural membranes and brain [23]. Many clinical studies have reported that providing DHA and AA in IF could improve vision and facilitate cognitive development [24, 25]. Some studies arrived at the conclusion that IF for term infants should consist of a minimum of $0.35 \%$ of total fatty acids as AA and $0.2 \%$ as DHA. The ratio of AA to DHA should be around 1.5. In the case of the preterm infants, IF should constitute $0.35 \%$ of DHA at least [26, 27].

\section{HMFA: need and significance}

The net absorption of saturated fatty acids in the small intestine is mostly regulated by the positional distribution of FAs in TAG molecule [28]. On relating the stool hardness to stool composition, Quinlan et al. concluded that the variations in the TAG palmitate content of IF and breast milk resulted in more soap formation in the infants who were fed with the IF, which resulted in harder stools [29]. It was found in a study that the addition of palm oil as a source 
of PA into IF resulted in a decreased absorption ratio of calcium and fat, which could reduce the mineral content of the infant's bones [30]. The effects of the palmitic acids in various stereoisomeric positions were studied by Carnielli et al., on both full-term and preterm infants. It was observed that the absorption of fatty acids and calcium was significantly higher in infant fed formulas which had TAGs similar to those found in human milk (i.e. PA esterified at $s n-2$ position) with respect to the infants fed with regular formulas (which had PA esterified mainly at $s n-1$ and $s n-3$ positions $[31,32]$. In another study, it was found that HMFA with PA at $s n-2$ position (i.e., similar to human milk) enhanced infant's WBBMC (whole-body bone mineral capacity), and reduced the formation of faecal calcium soaps, thus resulting in softer stools [33]. These studies and researches arrived at a common conclusion that TAG whose structure is somewhat identical to that in the HMF in IF, results in better absorption of fats and calcium and is beneficial for infants. Hence, the FA composition and TAG distribution have recently gained so much attention.

\section{HMFA and their classification}

Earlier, the term Human Milk Fat Analogue/Substitute (HMFA/S) was mainly confined to structured triacylglycerols, with PA at the $s n$-2 position. Recently, many studies have revealed the human milk's distinctive composition of lipids and their potential benefits for infants. As a result of this, many functional lipids have been developed and have emerged as an essential ingredient of the IF. All the lipids which are developed in order to mimic the nutritive functions of the HMF can be termed as HMFA. Characteristics of commonly preferred HMFA, classified on their lipid structures are listed in Table 1, which are based on the categories of the LMSD (Lipid MAPS Structure Database) [34].

\section{HMFA and their enzymatic production}

Developing and producing novel lipids which resemble the HMF and their assimilation and integration in the IF has been challenging for the food industry. The major TAG in HMF is OPO (1,3-Dioleoyl-2-palmitoyl-glycerol), and therefore it has been the target TAG in synthesizing HMFA. However, incorporation of FAs other than oleic acids at $s n-1,3$ positions in TAGs has been reported to have favourable effects on infants. These fatty acids include DHA, ARA, and some other LCPUFAs. These modified lipids are called "tailor-made lipids" or structured lipids (SLs). They can be developed with the aid of lipase enzymes (triacylglycerol acyl-hydrolase; E.C.3.1.1.3.). 
Acylglycerols are hydrolyzed via the aid of the lipase enzyme, which naturally catalyze the hydrolysis reaction at the water/oil interface. In the case of a non-aqueous media, they efficiently catalyze esterification and interesterification reactions, under low water activity. Lipases do not need any cofactors and are known to exhibit high stereospecificities, regiospecificities, typospecificities and substrate specificities and are considered a better catalyst over the classical chemical catalysts while forming very fewer side products. For executing a lipase-catalyzed reaction for producing HMFA, some of the crucial aspects that may be taken into consideration are (i) type of reaction; (ii) biocatalyst; (iii) reaction operation mode; and (iv) reaction medium composition. The novel structure and properties of HMFAs cannot be attained by chemical catalysts. The most accustomed approaches for lipase-catalyzed reactions are listed in Table 2.

\subsection{Reactions involved in HMFA production}

Most studies concerned with synthesizing HMFA are conducted in a one-step process involving an interesterification or an acidolysis reaction $[35,36]$. A reaction between a TAG and a single FFA (free fatty acid) or blends of FFAs is termed as an "acidolysis" reaction. The acidolysis reaction carried by an enzyme is generally considered as a reversible two-step reaction in which the ester bonds are hydrolyzed and FA is released, followed by FFA esterification to the glycerol backbone. Because of reaction kinetics, the maximum FA incorporation on reaching equilibrium is usually lower than $50 \mathrm{~mol}-\%$, in case of acidolysis, which is lower in comparison to the theoretically expected 66 mol-\%, when $s n-1,3$ specific lipases are used [37].

For the production of HMFA, TAGs which are rich in PA at $s n-2$ position are required. At the laboratory scale, tripalmitin with high purity is preferred. Since the tripalmitin with high purity is very expensive, cheap fats and natural oils like butterfat, lard, palm oil or palm stearin have been used as a substitute of PA at $s n-2$ position. Oleic acid or other FFAs, in blends or single from different vegetable oils like soybean, sunflower, coconut, hazelnut, safflower oil, are used an FFA source and fish oils used as a source of omega-3 PUFA, mainly DHA (Table 2). The FAs at $s n-1,3$ positions in the original TAGs are either completely or partially replaced by the FFA from the reaction medium, due to the regiospecificity of the lipase used for the production of HMFA. At the end of the reaction, the FFA released from the original TAGs and the unconverted FFA is removed via distillation in order to eliminate the residual tripalmitin as it will have a negative effect on the absorption of fat by the infants. Trisaturated TAGs are 
removed by crystallization at low temperatures rather than the wet fractionation method, which is not economical and requires more time and energy.

The interesterification reaction between tripalmitin and other oils that contain PA at $s n-2$ position has been performed as an alternative to the acidolysis. A final blend of different TAGs with somewhat identical physical properties like crystallization pattern and melting point is obtained via the interesterification reaction, making it difficult for the recovery of the fraction of TAGs which resemble the HMF. Hence the proportions of various oils in these blends and the choice of suitable blends are a crucial step for the achievement of the final product, which mimics the HMF [38].

\section{Accomplishments in designing and production of HMFA}

In recent years, enzymatic interesterification reaction to produce HMFA has gained significant attention. Alternative to the chemical interesterification, lipases (E.C. 3.1.1.3.) are being widely used to restructure lipids/fats/oils for augmenting the chemical, physical and nutritional properties. Several HMFAs have been designed and developed and have been very well documented. These fat substitutes are now being widely used in the food industry for the production of IF. Some of the noteworthy achievements in designing and production have been discussed further

\subsection{Preparation of HMFA from basa catfish oil}

The preparation of HMFA from basa catfish oil having a high degree of similarity to HMF was accomplished by physical blending and enzymatic acidolysis. The enzyme used for enzymatic acidolysis was Lipozyme RM IM. FFAs from Sunflower oil and Rick Simpson oil in the ratio of $1: 1$ was used as acyl donors to enhance the $\% s n-2$ PA in the acidolysis step. The reaction conditions were determined as $8 \mathrm{wt} \%$ enzyme load, $40^{\circ} \mathrm{C}$ temperature, 1:3 substrate molar ratio, $3.5 \mathrm{wt} \%$ water content, and 2 hours of reaction time. The \%sn-2 PA of the enzymatic product was enhanced from 50.2 to $67.7 \%$, and the linolenic acid content was enhanced from 9.7 to $23.2 \%$, under the given conditions. Based on the chemical composition of HMF, flaxseed oil, sunflower oil, palm kernel oil, palm stearin, algal, and microbial oils were selected in the physical blending stage. The optimization of the ratio of these oils to the enzymatic product was done by the physical blending model. The end product had a $98.2 \%$ similarity of FA, $80.8 \%$ similarity of $s n-2$ FA, $60.9 \%$ similarity of PUFA and $53.3 \%$ similarity of TAGs with respect to the HMF [39]. 


\subsection{Preparation of HMFA from vegetable oil blend}

Lipozyme® TL IM, a lipase enzyme obtained from Themomyces lanuginosa was used to catalyze the interesterification reaction of palm oil, palm kernel oil, olive oil, sunflower oil, and marine oil blend. These oils were formulated in the mass ratio of 4.0:3.5:1.0:1.5:0.2. The interesterification reaction was carried out in order to obtain a product which was analogous to the TAG structure of the HMF. The FA composition of the interesterified blend was somewhat similar to the HMF, especially, sn-1.3 positions consisted of unsaturated FAs, mainly oleic acid. The distribution of FAs at the $s n-2$ position was, however, a bit different. The proportion of PA was not at the desired level, but despite this, the study suggested that enzymatic interesterification with 1,3-specific lipase, on an oil blend, which consisted of oils and fats with high amount of PA at sn-2 position, can be used in the process of obtaining HMFA [40].

\subsection{Preparation of HMFA from palm stearin}

With the combination of Lipozyme RM IM catalyzed acidolysis of interesterified palm stearin with FAs from rapeseed oil and blending of the enzymatic product, HMFA was prepared. The enzymatic product had $39.6 \% \mathrm{PA}$, and $83.7 \%$ of the FAs at the $s n-2$ position were palmitic acid. The distribution probability of PA at the $s n-2$ position was $70.5 \%$ among the total PA. The content of AA was $0.4 \%$, and that of DHA was $0.3 \%$. The similarity between the final product obtained and HMF was found to be $89.2 \%$, thus suggesting that it could be utilized in IF production [41].

\subsection{Preparation of HMFA from stearidonic acid-enriched soybean oil}

In order to increase the intake of omega-3-FAs, SDA (stearidonic acid, C18:4n-3) enriched oil is preferred in the diet. HMF accounts for around $60 \%$ of PA, by weight. This PA is esterified at the $s n-2$ position to enhance the calcium and fat absorption in infants. The enzymatic interesterification of SDA soybean oil along with tripalmitin resulted in structured lipids, that had abundant PA at the $s n-2$ position of the TAG. Lipozyme TL IM or Novozym 435 were used for catalyzing the reactions under various conditions of temperature, substrate molar ratio, and time. By using either of the enzymes, structured lipids consisting of more than $60 \%$ PA at $s n-2$ position and containing more than $6 \%$ of total SDA. The structured lipids, thus obtained, could be used as ingredients in the production of IF [42]. 


\subsection{Preparation of HMFA by palm stearin and fish oil}

Palm stearin derived PSF (palm stearin fractionate) was further fractionated with solvents and was interesterified with n-3 PUFA rich fish oil at 1:1, 1:2, 1:3, 2:1 and 3:1 substrate molar ratios. The reaction was catalyzed by lipase enzyme extracted from Thermomyces lanuginosa, in order to derive a product with TAG, which shares its similarities with the HMF. The parameters, including the molar ratio and time, were standardized, and the enzyme concentration along with temperature was fixed at $10 \mathrm{wt} \%$ and $60^{\circ} \mathrm{C}$, respectively. The reaction was carried out in a stirred tank reactor, which was equipped with a magnetic stirrer. The desired product with $75.98 \%$ of PA at $s n-2$ position, $0.27 \%$ AA, $4.25 \%$ DHA and $3.43 \%$ EPA, with a melting point of $42^{\circ} \mathrm{C}$ was produced from the blend of PSF and fish oil at 2:1 molar ratio with $69.70 \%$ PA content after 12 hours of reaction. The study suggested a successful preparation of TAG containing distinctive FA composition, which was somewhat suitable to be used as an ingredient of IF [43].

\section{Conclusion}

HMF is the best nutrition source for infants in their first six months. It is a very complex mixture of several natural lipids. A great accomplishment was reached over the past few decades in the investigation of the composition of human milk and its nutritional benefits to infants, which promoted the development of HMFAs. One of the major challenges in developing the HMFA is the evaluation of their nutritional benefits on infants. In order to better understand the lipid digestion, development of in-vitro digestion models might be very useful. Another challenging aspect of HMFA production is its high cost. Several novel ingredients and their sources (like oils and fats) are being studied and investigated, in order to achieve an economical product. Complete nutritional requirements, necessary for long-term health and proper development of the infants may be fulfilled by the upcoming studies and future researches. 


\section{Acknowledgements}

KR thanks IIEST, Shibpur, Howrah, West Bengal, India

\begin{tabular}{|l|l|}
\hline \multicolumn{2}{|c|}{ Abbreviations } \\
\hline HMFA & Human Milk Fat Analogue \\
\hline HMFS & Human Milk Fat Substitute \\
\hline DHA & Docosahexanoic Acid \\
\hline PA & Palmitic Acid \\
\hline FFA/FA & Free Fatty Acid/Fatty Acid \\
\hline AA & Arachidonic Acid \\
\hline TAG & Triacylglycerol \\
\hline HMF & Human Milk Fat \\
\hline LCPUFA & Long Chain Poly-unsaturated Fatty Acid \\
\hline SL & Structured Lipid \\
\hline LMSD & Lipid MAPS structure database \\
\hline OPO & 1,3-dioleoyl-2-palmitoyl-glycerol \\
\hline SDA & Stearidonic Acid \\
\hline
\end{tabular}




\section{References:}

1. Victora, C.G., et al., Breast-feeding in the 21st century: epidemiology, mechanisms, and lifelong effect. The Lancet, 2016. 387(10017): p. 475-490.

2. Jensen, R.G., The lipids of human milk. 2018: CRC Press.

3. Jensen, R.G., The lipids in human milk. Progress in lipid research, 1996. 35(1): p. 53-92.

4. Kallio, H., et al., Triacylglycerol regioisomers in human milk resolved with an algorithmic novel electrospray ionization tandem mass spectrometry method. Food chemistry, 2017. 233 : p. 351-360.

5. Liu, Z., S. Rochfort, and B. Cocks, Milk lipidomics: What we know and what we don't. Progress in lipid research, 2018. 71: p. 70-85.

6. $\mathrm{Mu}, \mathrm{H}$. and C.-E. Høy, The digestion of dietary triacylglycerols. Progress in lipid research, 2004. 43(2): p. 105-133.

7. Talbot, G., Specialty oils and fats in food and nutrition: properties, processing and applications. 2015: Woodhead Publishing.

8. Fomon, S.J., Infant feeding in the 20th century: formula and beikost. The Journal of nutrition, 2001. 131(2): p. 409S-420S.

9. Fomon, S.J., Nutrition of normal infants. 1993: Mosby-Year Book, Inc.

10. Obladen, M., Historic records on the commercial production of infant formula. Neonatology, 2014. 106(3): p. 173-180.

11. $\mathrm{Mu}, \mathrm{H}$. and T. Porsgaard, The metabolism of structured triacylglycerols. Progress in lipid research, 2005. 44(6): p. 430-448.

12. Bornscheuer, U.T., Enzymes in lipid modification: Past achievements and current trends. European journal of lipid science and technology, 2014. 116(10): p. 1322-1331.

13. Xu, X., Production of specific-structured triacylglycerols by lipase-catalyzed reactions: a review. European journal of lipid science and technology, 2000. 102(4): p. 287-303.

14. Adlercreutz, P., Enzyme-catalysed lipid modification. Biotechnol Genet Eng Rev, 1994. 12: p. 231-54.

15. Yaqoob, P., CC Akoh (Ed.), Handbook of Functional Lipids, CRC Press, Taylor \& Francis Group, ISBN 0-8493-2162X, 525pp. 2007, Elsevier.

16. Jensen, R.G., Handbook of milk composition. 1995: Academic press.

17. Nommsen, L.A., et al., Determinants of energy, protein, lipid, and lactose concentrations in human milk during the first 12 mo of lactation: the DARLING Study. The American journal of clinical nutrition, 1991. 53(2): p. 457-465.

18. Grote, V., et al., Breast milk composition and infant nutrient intakes during the first 12 months of life. European journal of clinical nutrition, 2016. 70(2): p. 250-256. 
19. Greer, F.R., Do breast-fed infants need supplemental vitamins? Pediatr Clin North Am, 2001. 48(2): p. 415-23.

20. Allen, L.H., B vitamins in breast milk: relative importance of maternal status and intake, and effects on infant status and function. Adv Nutr, 2012. 3(3): p. 362-9.

21. Delplanque, B., et al., Lipid quality in infant nutrition: current knowledge and future opportunities. Journal of pediatric gastroenterology and nutrition, 2015. 61(1): p. 8.

22. Brenna, J.T., et al., Docosahexaenoic and arachidonic acid concentrations in human breast milk worldwide. The American journal of clinical nutrition, 2007. 85(6): p. 1457-1464.

23. Koo, W.W., Efficacy and safety of docosahexaenoic acid and arachidonic acid addition to infant formulas: can one buy better vision and intelligence? Journal of the American College of Nutrition, 2003. 22(2): p. 101-107.

24. Birch, E.E., et al., Visual maturation of term infants fed long-chain polyunsaturated fatty acid-supplemented or control formula for $12 \mathrm{mo}$. The American journal of clinical nutrition, 2005. 81(4): p. 871-879.

25. Innis, S.M., J. Gilley, and J. Werker, Are human milk long-chain polyunsaturated fatty acids related to visual and neural development in breast-fed term infants? The Journal of pediatrics, 2001. 139(4): p. 532-538.

26. Koletzko, B., et al., Long chain polyunsaturated fatty acids (LC-PUFA) and perinatal development. Acta paediatrica, 2001. 90(4): p. 460-464.

27. Fleith, M. and M. Clandinin, Dietary PUFA for preterm and term infants: review of clinical studies. Critical reviews in food science and nutrition, 2005. 45(3): p. 205-229.

28. Maduko, C., C. Akoh, and Y. Park, Enzymatic interesterification of tripalmitin with vegetable oil blends for formulation of caprine milk infant formula analogs. Journal of dairy science, 2007. 90(2): p. 594-601.

29. Quinlan, P., et al., The relationship between stool hardness and stool composition in breastand formula-fed infants. Journal of pediatric gastroenterology and nutrition, 1995. 20(1): p. 81-90.

30. Koo, W.W., E.M. Hockman, and M. Dow, Palm olein in the fat blend of infant formulas: effect on the intestinal absorption of calcium and fat, and bone mineralization. Journal of the American College of Nutrition, 2006. 25(2): p. 117-122.

31. Carnielli, V.P., et al., Feeding premature newborn infants palmitic acid in amounts and stereoisomeric position similar to that of human milk: effects on fat and mineral balance. The American journal of clinical nutrition, 1995. 61(5): p. 1037-1042.

32. Carnielli, V.P., et al., Structural position and amount of palmitic acid in infant formulas: effects on fat, fatty acid, and mineral balance. Journal of pediatric gastroenterology and nutrition, 1996. 23(5): p. 553-560. 
33. Kennedy, K., et al., Double-blind, randomized trial of a synthetic triacylglycerol in formulafed term infants: effects on stool biochemistry, stool characteristics, and bone mineralization. The American journal of clinical nutrition, 1999. 70(5): p. 920-927.

34. Sud, M., et al., Lmsd: Lipid maps structure database. Nucleic acids research, 2007. 35(suppl_1): p. D527-D532.

35. Ferreira-Dias, S., et al., The potential use of lipases in the production of fatty acid derivatives for the food and nutraceutical industries. Electronic Journal of Biotechnology, 2013. 16(3): p. 12-12.

36. Soumanou, M.M., M. Pérignon, and P. Villeneuve, Lipase-catalyzed interesterification reactions for human milk fat substitutes production: A review. European Journal of Lipid Science and Technology, 2013. 115(3): p. 270-285.

37. Xu, X., Engineering of enzymatic reactions and reactors for lipid modification and synthesis. European Journal of Lipid Science and Technology, 2003. 105(6): p. 289-304.

38. Ferreira-Dias, S. and C. Tecelão, Human milk fat substitutes: advances and constraints of enzyme-catalyzed production. Lipid Technol 26 (8): 183-186. 2014.

39. Zou, X., et al., Preparation of human milk fat substitutes from basa catfish oil: Combination of enzymatic acidolysis and modeled blending. European Journal of Lipid Science and Technology, 2016. 118(11): p. 1702-1711.

40. Karabulut, I., et al., Human milk fat substitute produced by enzymatic interesterification of vegetable oil blend. Food Technology and Biotechnology, 2007. 45(4): p. 434.

41. Zou, X.Q., et al., Preparation of human milk fat substitutes from palm stearin with arachidonic and docosahexaenoic acid: combination of enzymatic and physical methods. $\mathrm{J}$ Agric Food Chem, 2012. 60(37): p. 9415-23.

42. Teichert, S.A. and C.C. Akoh, Stearidonic acid soybean oil enriched with palmitic acid at the sn-2 position by enzymatic interesterification for use as human milk fat analogues. Journal of agricultural and food chemistry, 2011. 59(10): p. 5692-5701.

43. Ghosh, M., et al., Preparation of human milk fat analogue by enzymatic interesterification reaction using palm stearin and fish oil. J Food Sci Technol, 2016. 53(4): p. 2017-24. 


\section{Figures and Tables:}

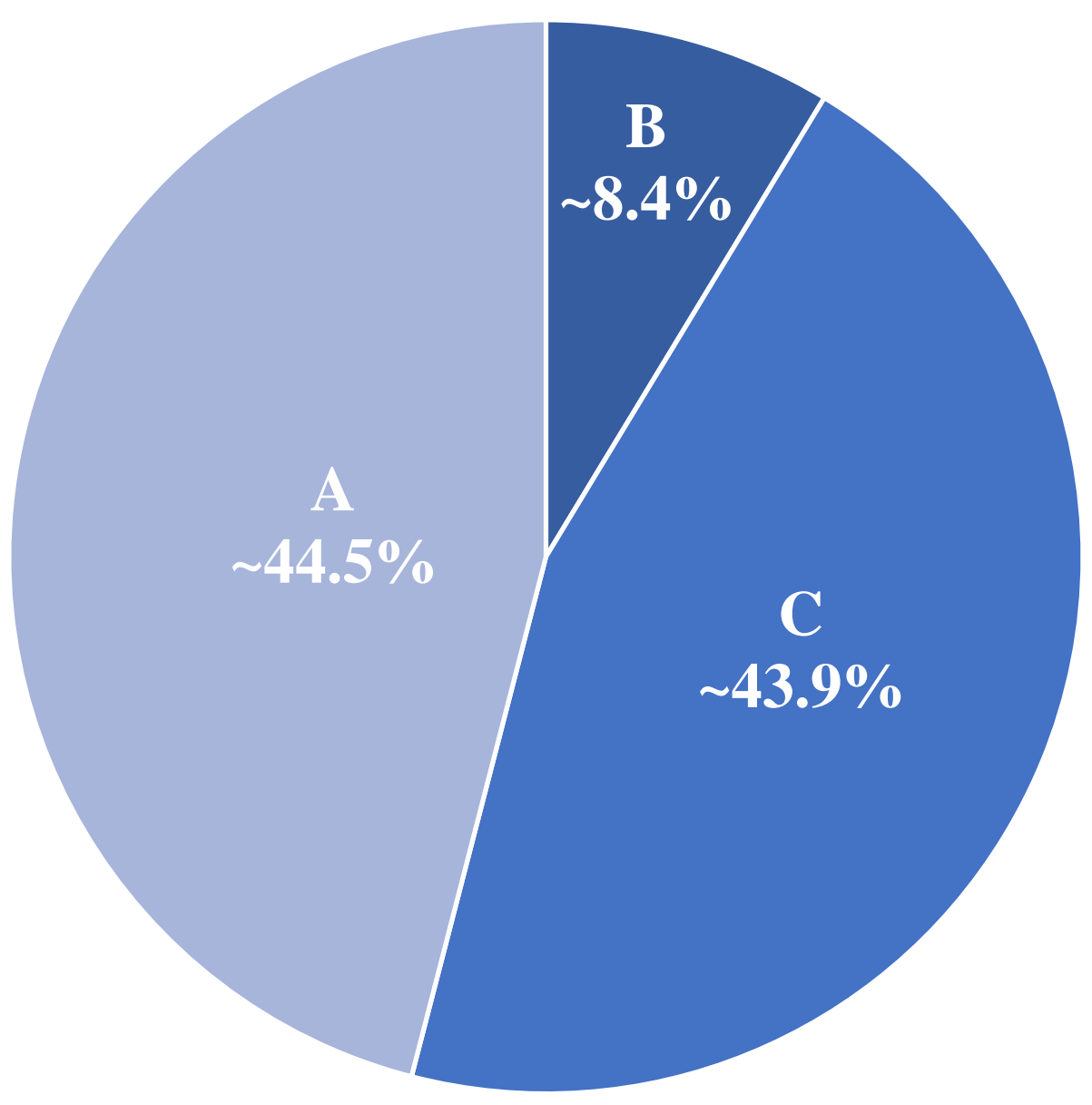

Figure 1: The approximate contributions of the prime macronutrients to total intake of energy in breast-fed infants (one month old). (A). Carbohydrates (B). Proteins (C). Lipids, contributing $44.5,8.4$, and $43.9 \%$ energy respectively. 


\begin{tabular}{|c|c|c|}
\hline Type of HMFA & $\begin{array}{l}\text { Classification in } \\
\text { LMSD } \\
\text { (composition) }\end{array}$ & Beneficial physiological aspects \\
\hline $\begin{array}{l}s n-2 \text { Palmitate } \\
\text { (OPO) }\end{array}$ & TAGs (glycerol-lipids) & $\begin{array}{l}\text { Particularly structured TAGs with PA } \\
\text { predominantly enriched at the } s n-2 \\
\text { position. } \\
\text { - May enhance softening of stools and } \\
\text { absorption of calcium. } \\
\text { - Usually designed by modifying } \\
\text { synthetic/natural TAGs with the aid of } s n \text { - } \\
1,3 \text { regioselective lipases. }\end{array}$ \\
\hline $\begin{array}{c}\text { MFGM } \\
\text { supplement }\end{array}$ & $\begin{array}{c}\text { Complex lipids } \\
\text { (glycerophospholipids } \\
\text { and sphingolipids) }\end{array}$ & $\begin{array}{l}\text { The tri-layer membranes of milk fat } \\
\text { globules consisting of sphingomyelin, } \\
\text { cholesterols, gangliosides, proteins and } \\
\text { various bioactive components. } \\
\text { May aid in optimal cognitive } \\
\text { development. } \\
\text { - These are primarily phospholipid mixtures } \\
\text { and bovine derived proteins extracted } \\
\text { from the dairy processing. }\end{array}$ \\
\hline $\begin{array}{c}\text { Long Chain } \\
\text { Polyunsaturated } \\
\text { Fatty Acid } \\
\text { (LCPUFA) }\end{array}$ & $\begin{array}{l}\text { Fatty Acids (fatty } \\
\text { acyls) }\end{array}$ & $\begin{array}{l}\text { Fatty acids composed of long carbon } \\
\text { chains (more than 20) with several double } \\
\text { bonds, primarily DHA and AA. } \\
\text { - May augment the development of neural } \\
\text { and visual functions of infant. } \\
\text { Mainly derived from sources like fish oil, } \\
\text { microbial fermentation and eukaryotic } \\
\text { algae. }\end{array}$ \\
\hline MCT & $\begin{array}{c}\text { Triacylglycerols } \\
\text { (glycerophospholipids) }\end{array}$ & $\begin{array}{l}\text { TAGs consisting of a large number of } \\
\text { medium-chain (mainly 8:0, 10:0 and 12:0) } \\
\text { fatty acids. } \\
\text { - Enhance lipid absorption and quick energy } \\
\text { source for metabolic syndromes in } \\
\text { children. } \\
\text { - The MCT products are generally derived } \\
\text { from tropical oils by the aid of } \\
\text { fractionation }\end{array}$ \\
\hline
\end{tabular}

Table 1: Characteristics of commonly preferred HMFA, classified on their lipid structures 


\begin{tabular}{|c|c|c|c|c|}
\hline Type of Reaction & $\begin{array}{l}\text { Steps } \\
\text { involved } \\
\text { in the } \\
\text { process }\end{array}$ & Enzymes involved & $\begin{array}{l}\text { Preferred } \\
\text { substrates }\end{array}$ & $\begin{array}{l}\text { Mode of } \\
\text { operation }\end{array}$ \\
\hline Interesterification & One & $\begin{array}{ll}\text { - } & \text { Lipozyme RM IM } \\
\text { - } & \text { Lipozyme TL IM } \\
\text { - } & \text { Novozym } 435\end{array}$ & 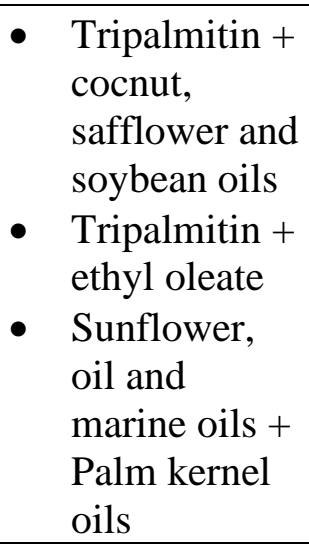 & 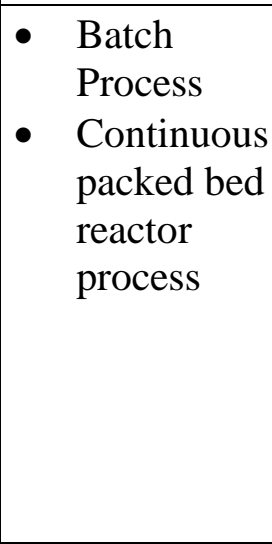 \\
\hline Acidolysis & One & $\begin{array}{l}\text { Non-commercial } \\
\text { immobilized lipases: } \\
\text { - } \quad \text { R-ROL } \\
\text { - } \quad \text { Carica papaya latex } \\
\text { - } \quad \text { Candida parapsilosis } \\
\text { lipase/acyltransferase } \\
\text { Immobilized } \\
\text { commercial lipases: } \\
\text { - } \quad \text { Lipozyme RM IM } \\
\text { - } \quad \text { Lipozyme TL IM } \\
\text { - } \quad \text { Novozym } 435\end{array}$ & $\begin{array}{l}\text { Single FFA } \\
\text { source: } \\
\text { - } \quad \text { Oleic acid } \\
\text { - } \quad \text { Stearidonic } \\
\quad \text { acid } \\
\text { - } \quad \text { DHA } \\
\quad \text { PA source: } \\
\text { - } \quad \text { Tripalmitin } \\
\text { - } \quad \text { Butterfat } \\
\text { - } \quad \text { Lard } \\
\text { - } \quad \text { Palm oil } \\
\text { Oils as source of } \\
\text { FFA: } \\
\text { - } \quad \text { Palm Kernel } \\
\text { - } \quad \text { Echium oil } \\
\text { - } \quad \text { Tea seed } \\
\text { - } \quad \text { Rapeseed } \\
\text { - } \quad \text { Soybean } \\
\text { - } \quad \text { Hazelnut } \\
\text { - } \quad \text { Omega-3 } \\
\quad \text { PUFA } \\
\end{array}$ & 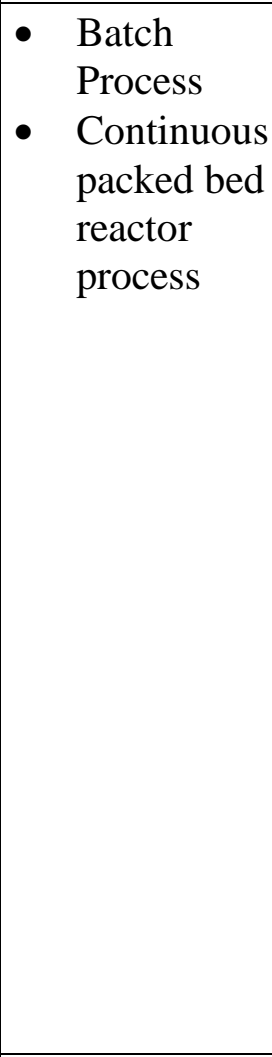 \\
\hline $\begin{array}{l}\text { Alcoholysis + } \\
\text { Esterification/Two } \\
\text { acidolysis }\end{array}$ & Two & $\begin{array}{ll}- & \text { Novozym } 435 \\
\text { - } & \text { Rhizopus delemar } \\
& \text { lipase } \\
\text { - } & \text { Rhizopus oryzae } \\
& \text { lipase } \\
\text { - } & \text { Lipozyme RM IM } \\
\end{array}$ & $\begin{array}{ll}\text { - } & \text { Palm stearin } \\
+ \text { oleic acid } \\
\text { - } & \text { Tripalmitin }+ \\
& \text { oleic acid }\end{array}$ & $\begin{array}{ll}\text { - } & \text { Batch } \\
& \text { process }\end{array}$ \\
\hline
\end{tabular}

Table 2: The most accustomed approaches for lipase-catalyzed reactions 